\title{
GUIDELINES FOR CONDUCTING POSITIVIST CASE STUDY RESEARCH IN INFORMATION SYSTEMS
}

\author{
Graeme Shanks \\ Department of Information Systems \\ The University of Melbourne \\ g.shanks@dis.unimelb.edu.au
}

\begin{abstract}
The case study research approach is widely used in a number of different ways within the information systems community. This paper focuses on positivist, deductive case study research in information systems. It provides clear definitions of important concepts in positivist case study research and illustrates these with an example research study. A critical analysis of the conduct and outcomes of two recently published positivist case studies is reported. One is a multiple case study that validated concepts in a framework for viewpoint development in requirements definition. The other is a single case study that examined the role of social enablers in enterprise resource planning systems implementation. A number of guidelines for successfully undertaking positivist case study research are identified including developing a clear understanding of key concepts and assumptions within the positivist paradigm; providing clear and unambiguous definitions of the units and interactions when using any theory; carefully defining the boundary of the theory used in the case study; using hypotheses rather than propositions in the empirical testing of theory; using fuzzy or probabilistic propositions in recognising that reality can never be perfectly known; selecting case studies carefully, particularly single case studies; and recognising that generalisation from positivist, single case studies is inherently different from generalisation from single experiments. When properly undertaken, positivist, deductive case study research is a valuable research approach for information systems researchers, particularly when used within pluralist research programs that use a number of different research approaches from different paradigms.
\end{abstract}

\section{INTRODUCTION}

The case study research approach is widely used within the information systems community. Case studies can be undertaken within a positivist or interpretivist paradigm, may be deductive or inductive, may involve single or multiple cases using literal or theoretical replication and may use qualitative and quantitative data (Cavaye, 1996). This paper focuses on positivist, deductive case study research in information systems.

Positivist, deductive case study research is well documented, with methodological guidelines published by Benbasat, Goldstein and Mead (1987), Lee (1989) and Yin (1994). Furthermore, key concepts and assumptions within the positivist paradigm are also well documented (for example see Guba and Lincoln (1994) and Neuman (2000)). Two recently published research studies based on a strictly positivist case study research approach provide useful exemplars of this type of research for the information systems community (Darke, 1997; Sarker and Lee, 2000). The first is a multiple, positivist case study that validated concepts in a framework for viewpoint development in requirements definition (Darke, 1997). The second is a single, positivist case study that examined the role of social enablers in Enterprise Resource Planning (ERP) systems implementation (Sarker and Lee, 2000). Both studies are reported in a rigorous manner including proposition formulation, deductive testing of the propositions and consideration of validity and reliability.

This paper first discusses the positivist research paradigm and presents precise definitions for key concepts including theory, proposition, hypothesis and hypothesis testing, and uses examples from Darke (1997) to illustrate the concepts. The following section discusses positivist case studies and how they may be conducted. The third section presents a description of the process and outcomes of Darke's study. The following section presents a description of Sarker and Lee's study, particularly focusing on their use of the outcomes of the study on critical success factors for ERP systems implementation by Parr et al, (1999) and how they were used in the development of propositions. The next section presents several guidelines for successfully undertaking positivist case study research based on a critical analysis of the two studies. The paper concludes with a discussion of the place for positivist case studies in information systems.

\section{THE POSITIVIST PARADIGM: THEORIES, PROPOSITIONS, HYPOTHESES AND HYPOTHESIS} TESTING

A paradigm is a set of beliefs about the nature of social reality, that is, the nature of the "world" and the individual's place in it (Guba and Lincoln, 1994; Shanks, Rouse and Arnott, 1993). Guba and Lincoln note that a paradigm has three dimensions:

- What is the form and nature of reality (the ontological question)?

- What is the relationship between the researcher and what can be known (the epistemological question)?

- How can the researcher find out if whatever they believe can be known (the methodological question)?

Paradigms are human constructions that are neither right nor wrong. They should be understood as assumptions that are not subject to proof: proponents must argue for their utility (Guba and Lincoln, 1994).

The positivist paradigm has the following positions with regard to the three dimensions (Guba and Lincoln, 1994; Shanks, Rouse and Arnott, 1993): 
- An objective reality is assumed which can be systematically and rationally investigated through empirical investigation, and is driven by general causal laws that apply, in particular, to social behaviour. This is sometimes called naïve realism (the ontological position).

- The researcher and the phenomena being investigated are assumed to be independent, and the researcher remains detached, neutral and objective. Any reduction in independence is a threat to the validity of the study, and should be reduced by following prescribed procedures (the epistemological position).

- General theories are used to generate propositions that are operationalised as hypotheses and subjected to empirical testing that is replicable. Hypotheses should be testable and provide the opportunity for confirmation and falsification. This is the essence of the scientific method (the methodological position).

In the following discussion about theory, proposition, hypothesis and hypothesis testing we assume a positivist position.

\section{Theories}

A theory is a system of ideas that abstracts and organises knowledge about the social world (Neuman, 2000). There are many types of theory including implicit (preconceptions, biases and values etc.) and explicit theory (sets of organised concepts and their interrelationships) (Miles and Huberman, 1994). There are highly abstract theoretical frameworks, and focused mid-range theories more suited to empirical work (Neuman, 2000). For empirical studies conducted using a positivist, deductive case approach mid-range, explicit theories are relevant. A theory of this type has three main elements (Dubin, 1978; Bacharach, 1989).

A set of well-defined units (or concepts);

3)

Laws of interaction (or interrelationships between the units);

A boundary within which the theory holds.

Dubin (1978) provides a full discussion of these elements, but for the purposes of this paper an example will be used to explain their meaning. Darke (1997) developed a theoretical framework for understanding viewpoint development within requirements definition that comprises four units, seven laws of interaction and a clearly articulated boundary. I will use part of this theoretical framework to explain Dubin's elements of a theory.

Two units of the theoretical framework are "Viewpoint Development Role" and "Viewpoint Representation". Each of these units is an enumerative unit, that is, a property characteristic of viewpoint development that must always be present. Further, they are attributive enumerative units as they are properties characteristic of viewpoint development in all conditions. The values of both units are used to identify types of that unit. Darke (1997) defines three values for viewpoint development roles: supporting requirements acquisition, supporting requirements modelling or supporting both phases of the requirements definition process, and three values for viewpoint representations: formal, semi-formal and informal.

Laws of interaction may be associational (the categorical interactions of Dubin (1978)), sequential (the sequential interactions of Dubin (1978)), and causal (the determinant interactions of Dubin (1978)). These three forms of interaction build on each other, so the associational laws are the most basic form of interaction. A stronger form of interaction is sequential (which subsumes associational), and the strongest from is causal (which subsumes sequential). Furthermore, causal interactions may be necessary or necessary and sufficient. Darke (1997) identifies a categorical, bi-directional law of interaction between the units "Viewpoint Development Role" and "Viewpoint Representation". The law of interaction is "Different viewpoint representations tend to be used during different viewpoint development roles". The two units and the law of interaction may be represented using a diagram as shown in Figure 1.

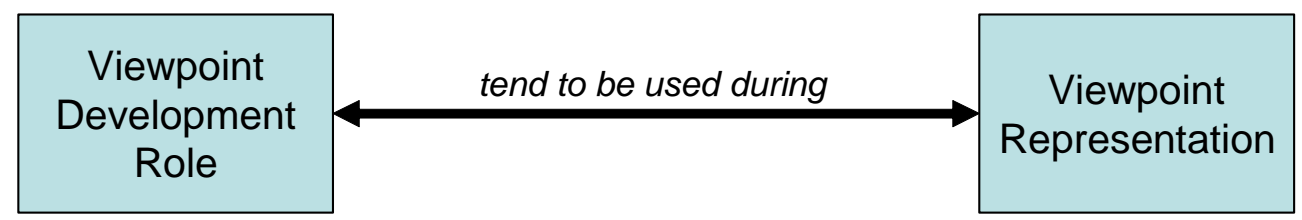

Figure 1: (Part of) the Viewpoint Development Theoretical Framework (Darke, 1997, p111)

The boundary of the theoretical framework specifies the portion of the world within which the units and laws of interaction hold. Darke (1997) specifies the boundary as viewpoint development within the domain of requirements definition.

\section{Propositions}

Predictions about the world are made using propositions, that is, conclusions that may be deduced logically from the theory. Propositions link the values of units. Propositions in the viewpoint development theoretical 
framework will therefore link specific values of viewpoint representation with specific values of viewpoint development role. Dubin (1978) notes that the most usual form of propositions is the "if ... then ..." format. One proposition identified by Darke (1997) that relates to the units shown above in Figure 1 is (adapted to the form suggested by Dubin):

- If representation techniques are informal or semi-formal then they tend to be used during the requirements acquisition viewpoint development role.

\section{Hypotheses}

A hypothesis is an empirically testable statement that is generated from a proposition. Terms in propositions belong to the abstract world of theory. Each of the terms must be assigned an empirical indicator. These empirical indicators are then substituted into the proposition to form a corresponding hypothesis. Once hypotheses have been generated they may be used in empirical studies.

Empirical indicators for informal representation techniques are text, rich pictures and animations. Empirical indicators for semi-formal representation techniques include data flow diagrams (DFDs), unified modelling language (UML) diagrams and entity relationship (ER) diagrams. Empirical indicators for requirements acquisition include elicitation, understanding and elaboration of information system requirements. Hence, a hypothesis (H1) generated from the first proposition and expressed in a form suitable for refutation is:

H1 Text, rich pictures, animation, DFDs, UML diagrams and ER diagrams tend to be used during elicitation, understanding and elaboration of information system requirements.

The hypothesis is clearly in a form that can be empirically tested. It is expressed in terms that support collection and analysis of empirical data in contrast to the proposition, which is expressed in terms of the theoretical framework. Terms used in the hypothesis are "things observable" (Dubin, 1978, p205). One proposition may generate many hypotheses; in fact $\mathrm{H} 1$ above could have been expressed as multiple hypotheses, each linking a pair of empirical indicators.

\section{Hypothesis Testing}

Hypotheses are tested by comparing their predictions with observed data. Observations that confirm a prediction do not establish the truth of a hypothesis. The deductive testing of hypotheses involves looking for disconfirming evidence to falsify hypotheses (Lee, 1989). Falsified hypotheses are then refined based on the reasons for falsification and subjected to further empirical testing.

\section{THE POSITIVIST APPROACH TO CASE STUDY RESEARCH IN INFORMATION SYSTEMS}

A case study is "an empirical enquiry that investigates a contemporary phenomenon within its real-life context, especially when the boundaries between phenomenon and context are not clearly evident" and it "relies on multiple sources of evidence" (Yin, 1994, p. 13). Case study research investigates pre-defined phenomena but does not involve explicit control or manipulation of variables: the focus is on in-depth understanding of a phenomenon and its context (Cavaye, 1996). Case studies typically combine data collection techniques such as interviews, observation, questionnaires, and document and text analysis. Both qualitative data collection and analysis methods (which are concerned with words and meanings) and quantitative methods (concerned with numbers and measurement) may be used (Yin, 1994, p. 14). Case study research may involve inductive theory building or have clear a priori definitions of variables to be studied and the ways in which they can be operationalised (Benbasat et al., 1987; Yin, 1994, p. 34).

Case study research needs to be distinguished from the use of case studies as teaching devices, where the purpose is to illustrate particular situations and provide a framework for discussion amongst students (Yin, 1994, p. 10). Teaching cases do not necessarily include a complete or accurate description of actual events, as case study details and materials may be changed in order to better illustrate a specific point. The criteria for developing high quality teaching cases are very different from those for producing high quality case study research (Yin, 1994, p. 2).

Case study research can be used to achieve various research aims: to provide descriptions of phenomena, develop theory, and test theory. Case study research has often been associated with description and with theory development, where it is used to provide evidence for hypothesis generation and for exploration of areas where existing knowledge is limited (Cavaye, 1996). Approaches such as grounded theory (Glaser \& Strauss, 1967), in which theoretical concepts and propositions emerge as the researcher gathers data and investigates phenomena, may be used to develop theory.

The use of case study research to test theory requires the specification of theoretical propositions and related testable hypotheses derived from an existing theory. The results of case study data collection and analysis are used to compare the case study findings with the expected outcomes predicted by the hypothesis (Cavaye, 1996). The theory is either validated or falsified and found to be inadequate in some way and may then be further refined on the basis of the case study findings. 
Case study research has been used within both the positivist and the interpretivist philosophical traditions (Cavaye, 1996; Doolin, 1996). Case study research within the positivist tradition is designed and evaluated according to the criteria of the natural science model of research: controlled observations, controlled deductions, replicability, and generalisability (Lee, 1989a). Although manipulation of variables in the experimental sense is not possible in case study research, theoretical constructs can be defined, operationalised and empirically evaluated, and naturally occurring controls can be identified (Lee, 1989; Cavaye, 1996). Literal and theoretical replication in multiple case study research provides for generalisability of case study research findings (Lee, 1989; Yin, 1994, pp. 46-51).

\section{Rigour in Positivist Case Study Research}

Validity and reliability in positivist case study research involves using clearly defined methodological guidelines for ensuring construct validity, internal validity, reliability and external validity (Lee, 1989; Yin, 1994).

Construct validity concerns the issue of whether empirical data in multiple situations leads to the same conclusions, and is improved by using multiple sources of evidence (to essentially provide multiple data points for the same phenomenon), having key informants review the case study report (to improve the accuracy of case study data) and establishing a chain of evidence so a reader can trace the chain of evidence (Yin, 1994).

Internal validity concerns the issue of whether empirical data provides information about the theoretical unit, and is achieved by using pattern matching to ensure that case study data cannot be explained by rival theories with different independent variables in the hypotheses (Yin, 1994).

Reliability concerns the stability and consistency of the study over time and is ensured by creating and maintaining a case study database and developing a clear case study protocol (Yin, 1994).

External validity concerns the generalisability of the findings of the study and is ensured by selecting "typical" cases (one or more cases that are representative of a large number of other cases) and selecting one or more cases that are likely to confirm the hypotheses, so that disconfirming evidence can be considered decisive (Markus, 1989).

\section{THE CASE STUDY OF DARKE (1997)}

The positivist case study reported by Darke concerns viewpoint development in requirements definition. A theoretical framework was first synthesised from the literature, comprising four units and seven laws of interaction. Elements of the theoretical framework were then subjected to empirical testing using a multiple case study approach.

\section{Theory and Propositions}

The theoretical framework in Darke's study is clearly defined and presented in considerable detail. The units and laws of interaction are well supported by an extensive synthesis of literature in information systems development, conceptual modelling and requirements engineering. Each of the units in the model has several values that identify types of the unit and are used in generating propositions. For example, the unit Viewpoint Representation has three values, formal, semi-formal and informal. The theoretical framework is shown in Figure 2 below.

Darke identifies seven bi-directional propositions that associate particular values of one unit with particular values of a second unit. Note that not all values need participate in propositions. 


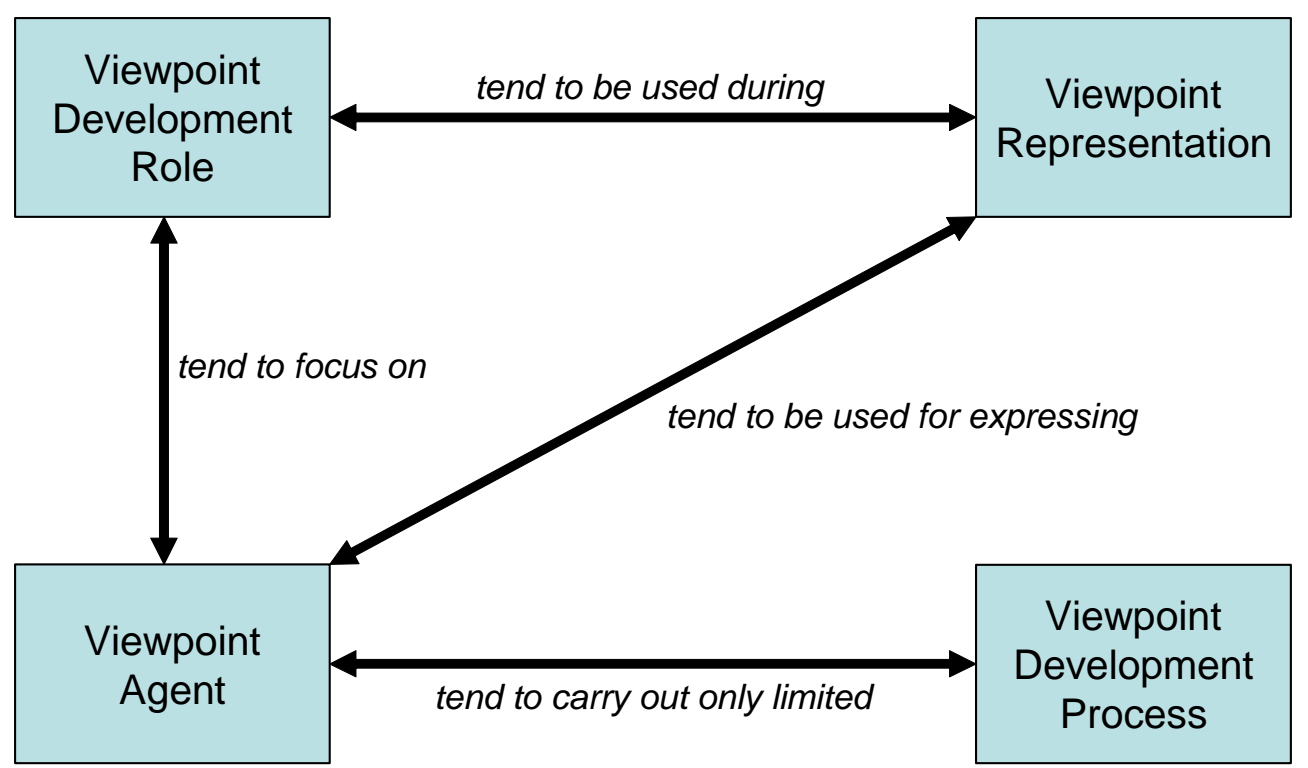

Figure 2: Viewpoint Development Theoretical Framework (Darke, 1997, p111)

Two of the seven propositions identified by Darke (1997) that will be used in this analysis are:

"P1 Informal and semi-formal viewpoint representation techniques tend to be used during viewpoint development supporting requirements acquisition” (Darke, 1997, p114)

"P2 Semi-formal and formal viewpoint representation techniques tend to be used during viewpoint development supporting requirements modelling” (Darke, 1997, p115)

These propositions are based on associational laws of interaction and are carefully worded to include an element of fuzziness by using the phrase "tend to be used during". An alternative and stronger wording would be "are used during”, however due to the tentative nature of the theoretical framework the fuzzier wording was deemed appropriate.

\section{Theory Testing using Multiple Case Studies}

Four case studies of the requirements definition phase of systems development projects were conducted in order to empirically test the theoretical framework and propositions. Literal replication was used in selecting the case study sites to allow cross-case comparison and strengthen the research findings by increasing the external validity of the study. The four cases were conducted in three different Australian organisations in the first half of 1997. Each case involved a large systems development project in which the requirements definition phase was either in-progress or recently completed. Data collection involved unstructured and semi-structured interviews with several people in different roles in the requirements definition process and access to documents about the project, requirements definition documents and annual reports and other published information about the organisations.

Data collection was carefully undertaken and a case study database maintained. Units in the theoretical framework guided qualitative data analysis to determine their applicability in practice. Units were considered applicable if case participants perceived them to be both relevant and meaningful or that units from the framework were present in the data. Both within-case and between case analysis was conducted using pattern matching qualitative data analysis techniques (Miles and Huberman, 1994).

Deductive testing of the validity of units in the theoretical framework and the seven propositions was reported by listing evidence from detailed descriptions of each of the four cases. Case study analysis confirmed the applicability of the four units in the theoretical framework and no additional units were identified. Evidence was found to support all seven propositions and one additional law of interaction between the viewpoint representation and viewpoint development process units.

\section{THE CASE STUDY OF SARKER AND LEE (2000)}

The positivist case study reported by Sarker and Lee (2000) concerns the role of "social enablers" in ERP systems implementation. Three propositions that identify necessary conditions for ERP systems implementation success are synthesised from relevant literature, and then subjected to empirical testing using a positivist, single case study approach. 


\section{Theory and Propositions}

Sarker and Lee do not provide an explicit theoretical framework in their study. However, an implicit theoretical framework may be inferred from the three propositions they synthesised:

"P1 ERP implementation can be successful only if there is a strong and committed leadership guiding the initiative” (Sarker and Lee, 2000, p416)

"P2 ERP implementation can be successful only if there is open and honest communication among the stakeholders" (Sarker and Lee. 2000, p416)

"P3 ERP implementation can be successful only if the implementation team is empowered and balanced” (Sarker and Lee, 2000, p416)

The implicit theoretical framework has two units, Social Enablers and ERP Implementation Outcome, and one causal law of interaction. The unit Social Enablers has three values, strong and committed leadership, open and honest communication and an empowered and balanced implementation team. The unit ERP Implementation Outcome has two values, success and failure. The "only if” label on the law of interaction corresponds to a "necessary" or relatively weak causal law. The implicit framework is shown in Figure 3 below.

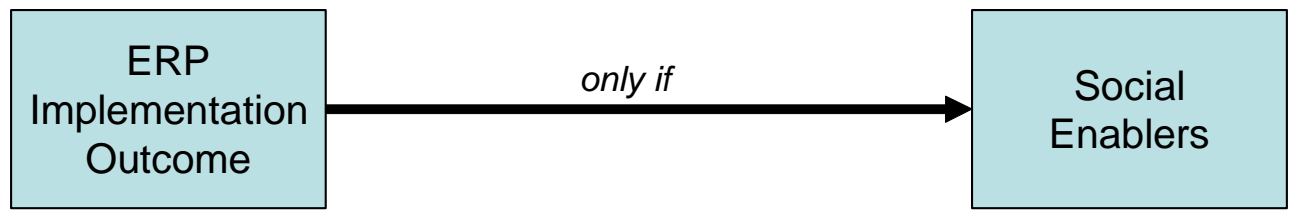

Figure 3: Implicit ERP Implementation Theoretical Framework

One of the key references used in the synthesis of the three propositions was Parr, Shanks and Darke (1999) in which critical success factors for ERP system implementation projects were identified. In this paper the scope of the ERP system implementation project was defined as the configuration and implementation of the ERP software package, and success was defined as the project meeting budget and time constraints. Critical success factors for successful ERP system implementation were elicited from interviews with 10 consultants each of whom had extensive experience in ERP system implementation. Four of the critical success factors identified as necessary for ERP system implementation success were used by Sarker and Lee (2000). Management support (or strong and committed leadership) was clearly identified by all interviewees as a necessary condition for ERP implementation success. Hence, proposition one of Sarker and Lee is strongly supported by the Parr et al. (1999) study. However, communication was identified as a necessary condition by only $50 \%$ of interviewees. Hence, the second proposition of Sarker and Lee was only weakly supported by the Parr et al. study. A balanced team was identified by $80 \%$ of interviewees as a necessary condition for successful ERP implementation; the support for empowered decision makers was not as strong. The third proposition of Sarker and Lee combines these two critical success factors and therefore is supported by the Parr et al. study but not nearly as strongly as management support (in the first proposition).

Sarker and Lee divide their ERP implementation process into three phases, of which only the second phase, "implementing ... the chosen ERP software", corresponds to the scope of ERP implementation used by Parr et al. in their study. The first phase concerns changes to the organisation prior to implementing the ERP software and the third phase concerns enhancements to the ERP system by adding further modules.

\section{Theory Testing using a Single Case Study}

The case study involved implementation of several modules of an ERP system in a medium sized manufacturing company, with offices throughout the United States of America and subsidiaries in Great Britain, Germany and Australia. Data collection included interviews with 17 people in various roles in the firm, attendance at several meetings associated with the ERP implementation, and access to documents about the company background and the ERP implementation project from 1996 to 1997.

Great care was taken to ensure rigour in the conduct of the case study. The guidelines listed previously in this paper were followed closely and reported clearly. For example, pattern matching in qualitative data analysis was used to ensure internal validity by matching predictions derived from propositions with patterns found in the data.

Success in ERP implementation was defined as follows: "we consider implementation to be successful if different stakeholders state or indicate through actions that such was the case” (Sarker and Lee, 2000, p 419). 
Sarker and Lee note that the concept of success is complex; no universally defined criteria exist and criteria vary with the phase of implementation.

Deductive testing of each proposition was reported by listing evidence from relevant empirical data and justifying a conclusion. Proposition P1 (strong and committed leadership) was validated, proposition P2 (open and honest communication) was refuted, and proposition P3 (empowered and balanced team) was refuted.

Based on these results, Sarker and Lee note the contradiction between the literature and the empirical evidence from the case study. They conclude that their case study presents a challenge to future ERP researchers to investigate the interactions between the three conditions used in the propositions and whether strong and committed leadership can compensate for the absence of the other social enablers.

\section{GUIDELINES FOR CONDUCTING POSITIVIST CASE STUDY RESEARCH}

Several guidelines for conducting positivist case study research emerge from the discussion of the positivist paradigm earlier in this paper and a critical analysis of the two positivist case studies described in the previous section.

\section{Develop a clear understanding of key concepts and assumptions within the positivist paradigm}

A deep understanding of the positivist paradigm and its underlying ontological, epistemological and methodological positions is crucial in conducting positivist case study research. The key concepts of theory (including units, laws of interaction and boundary), proposition, hypothesis and hypothesis testing need to be clearly defined and understood. The process of designing and conducting positivist case study research in information systems and guidelines for ensuring validity and reliability are well documented (Lee, 1991; Yin, 1994). Both Darke (1997) and Sarker and Lee (2000) have generally been very thorough in undertaking and reporting their studies, although a critical analysis reveals some important issues that lead to the remaining guidelines.

\section{Provide clear and unambiguous definitions of the units and interactions in the theory}

Darke takes great care in rigorously and completely defining her theoretical framework. All units in the framework are clearly and unambiguously defined. The laws of interaction are also clearly defined and well supported by relevant literature. Sarker and Lee do not propose a "theory" per se; they synthesise three propositions from a selection of the ERP system implementation literature. However, there is an implicit theory that includes two units and one interaction.

While there is some discussion about each of the three social enablers and reference to relevant literature, Sarker and Lee do not provide precise definitions for these units. Of greater concern is the definition provided for success in ERP system implementation, relying on stakeholders indicating, "through [their] actions that such was the case". Parr et al. (1999) define success in ERP implementation to be "the meeting of budgetary and time constraints". This is clearly different to the definition of success offered by Sarker and Lee. The concept of success in ERP system implementation is complex, relative and changes over time (Markus \& Tanis, 1999, Markus et al, 2000). Clear definitions of the units and values are required to ensure the validity and reliability of case study research.

\section{Carefully define the boundary of the theory used in the case study}

Darke provides a clear definition for the boundary of her theoretical framework by articulating the scope as viewpoint development within the domain of requirements definition. This defines the boundary within which the theoretical framework applies and the limits to which outcomes from the study can be generalised.

Sarker and Lee define the boundary of their case study as the three phases of ERP systems implementation: changes to the organisation prior to implementing the ERP software, implementing the ERP software, and enhancements to the ERP system. This is inconsistent with the scope of the factors necessary for ERP implementation success identified by Parr et al. (1999). Parr et al. limited their study to implementing the ERP software, or phase two only of the Sarker and Lee study. Interestingly, case study data from phase two of the Sarker and Lee study does not provide strong evidence to refute any of the three propositions. Clearly, when synthesising propositions from the literature, care should be taken to ensure the scope of the studies are the same or very similar.

\section{Use hypotheses (not propositions) in empirical testing}

Propositions are predictions about the world that may be deduced logically from theory. Values of units that appear in propositions should be operationalised before empirical testing can be conducted. Each of the values must be assigned an empirical indicator. These empirical indicators are then substituted into the proposition to form a corresponding hypothesis. Once hypotheses have been generated they may be used in empirical studies. 
Darke uses propositions in her empirical study and does not explicitly define and test hypotheses. However, in the detailed description of her case studies, it is apparent that indicators for each of the values used in her propositions exist and could have been explicitly used. For example, empirical indicators for the unit semiformal representation techniques included in the case study description are data flow diagrams, unified modelling language diagrams and entity relationship diagrams. Use of hypotheses and empirical indicators in the case study would have strengthened the rigour and validity of the study.

In their case study, Sarker and Lee also directly test propositions rather than first converting them to hypotheses. They did not identify empirical indicators for strong and committed leadership, open and honest communication, an empowered and balanced team, and ERP implementation success. Furthermore, there is limited detail in the case study description other than a number of quotes from interviewees that generally relate to units in the propositions. Two empirical indicators for "success" as defined by Parr et al. (1999) that could have been used are that the project is completed on time and within budget. Direct testing of propositions with imprecise definitions of values and empirical indicators reduces the rigour of the study and leads to imprecision in findings.

\section{Consider using fuzzy or probabilistic propositions and embrace post-positivism}

The two case studies described in this paper have very different types of propositions. Darke (1997) develops an associational law of interaction with the label "tends to be used during”. This introduces an element of fuzziness into the proposition that strongly influences the subsequent data analysis in empirical testing. In contrast, Sarker and Lee (200) develop causal laws of interaction with the label "only if” (a necessary condition). Compared to Darke's laws of interaction, this is a relatively strong law of interaction. Hypotheses involving causal laws of interaction with the label "if and only if" (both necessary and sufficient) could be easily refuted by selecting specific case situations. In case study research where contextual circumstances are prevalent, strong laws of interaction do not take into account our imperfect knowledge of reality and our inability to be objective and detached, particularly in social situations.

In response to these issues many researchers have embraced post-positivism, which relaxes the philosophical assumptions of positivism. Guba and Lincoln (1994) offer the following three amendments to the dimensions of positivism in defining post positivism:

- An objective reality is imperfectly knowable (critical realist ontological position).

- A subjective researcher can only know about reality to a degree of probability (modified dualist epistemological position).

- A modified experimental method is used including hypothesis refutation using both quantitative and qualitative methods (modified experimental methodological position).

In recognising the uncertainty about what can be known, propositions need to have a "degree of uncertainty" or fuzziness about them.

\section{Select case study sites carefully, particularly single case study sites}

It is crucial in designing case study research to carefully select case study sites. For multiple case studies, case study site selection should be justified using either literal or theoretical replication. It is important to be very clear about why particular sites are selected and how they contribute to the overall research design. Darke used literal replication to select four case studies that were similar in size, nature and complexity.

Positivist, single case studies should be very carefully selected. Yin (1994) argues that single case studies should be unique and revelatory. That is, they are best used in unusual circumstances. However, Lee (1989) takes a different position and argues that a single, positivist case study can be used more generally. However, when testing hypotheses in positivist, single case studies, care must be taken to select a typical, representative case study site if the results are to be generalised.

\section{Generalisation from single case studies is inherently different to generalising from experiments}

Lee (1989) argues that a single, positivist case study is similar to a single experiment. He further argues that the output of a single experiment is not generalisable beyond the set of empirical circumstances encountered in the experiment (Lee, 1989). Additional experiments with different empirical circumstances that confirm a theory strengthen and extend the generalisability of the theory. Similarly, no theory would be generalisable on the basis of a single case study; generalisability is strengthened when the theory is tested on other empirical circumstances (Lee, 1989).

This argument ignores the fact that experiments can be carefully designed with controls and random assignment of participants to different treatment groups. These experimental designs and statistical analysis techniques are intended to strengthen the generalisability experimental outcomes. In an experiment each participant is subjected to a treatment and separately measured. A single case study is very different. Participants are separately interviewed in data collection but their responses are consolidated at "unit of analysis” level. For 
example, in Sarker and Lee's (2000) case study, the concept of ERP implementation success is determined for each phase of the process of ERP implementation by consolidating evidence from several participants. They each contribute to a single view of "success".

\section{CONCLUSION}

The guidelines presented in the previous section are of great significance for information systems researchers and for reviewers assessing positivist, deductive case study research. They suggest that information systems researchers undertaking positivist, deductive case research should:

1. Develop a clear understanding of key concepts and assumptions within the positivist paradigm including theory, proposition, hypothesis and hypothesis testing;

2. Provide clear and unambiguous definitions of the units and interactions when using any theory;

3. Carefully define the boundary of any theory used in the case study;

4. Use hypotheses rather than propositions in empirical testing of theory;

5. Consider using fuzzy or probabilistic propositions and move to post-positivism;

6. Carefully select case study sites, particularly single case study sites;

7. Recognise that generalisation from positivist, single case studies is inherently different from generalisation from single experiments.

Positivist, deductive case studies are an important research approach within information systems. They provide a very sound and systematic approach for conducting research and may be used in conjunction with other approaches to provide richer and more reliable research results. Different approaches to research within information systems each provide value and should be seen as complementary to each other. Mingers (2001) encourages the design of research programs that use a number of different research approaches from different paradigms. Positivist, deductive case studies are an important component of such pluralist approaches to information systems research.

\section{REFERENCES}

Bacharach, S.B. (1989) Organisational Theories: Some Criteria for Evaluation, Academy of Management Review, 14(4), 496-515

Benbasat, I., Goldstein, D.K. \& Mead, M. (1987) “The Case Research Strategy in Studies of Information Systems”, MIS Quarterly, 11, 369-386.

Cavaye, A.L.M. (1996) “Case Study Research: A Multi-faceted Research Approach for IS”, Information Systems Journal, 6, 227-242.

Darke, P., (1997) Viewpoint Development in Requirements Definition, unpublished PhD Thesis, Monash University

Darke, P., Shanks, G. and Broadbent, M. (1998) "Successfully Completing Case Study Research: Combining Rigour, Relevance and Pragmatism”, Information Systems Journal, 8, 273-289

Doolin, B. (1996) “Alternative Views of Case Research in Information Systems”, Australian Journal of Information Systems, 3(2), pp 21-29

Dubin, R. (1978) Theory Building, Free Press, New York

Glaser, B. G. \& Strauss, A. L. (1967) The Discovery of Grounded Theory: Strategies for Qualitative Research, Aldine: Chicago

Guba, E.G. and Lincoln, Y.S. (1994) “Competing Paradigms in Qualitative Research”, in N.K. Denzin and Y.S. Lincoln (eds) Handbook of Qualitative Research, Sage Publications, Thousand Island, 105-117

Lee, A.S. (1989) “A Scientific Methodology for MIS Case Studies”, MIS Quarterly, 13, 33-50.

Lee, A. S. (1991) “Integrating Positivist and Interpretive Approaches to Organizational Research”, Organization Science, 2(4), pp 342-365

Markus, L. (1989) “Case Selection in Disconfirmatory Case Studies”, in J. Cash and M. Lawrence (eds) The Information Systems Research Challenge, Vol 1, Harvard Business School, 20-26

Markus, M.L. and Tanis, C (1999) The enterprise systems experience - from adoption to success. In Zmud, R.W. (ed.) Framing the Domains of IT Research: Glimpsing the Future Through the Past, Pinaflex Educational Resources, Cincinatti OH: 173-207

Markus, M. L., Tanis, C. \& van Fenema, P. C. (2000) “Multisite ERP Implementations” Communications of the ACM, 43(4), pp 42-46

Miles, M.B. \& Huberman, A.M. (1994) Qualitative Data Analysis: A Sourcebook of New Methods, Sage Publications, Newbury Park

Mingers, J. (2001) “Combining IS Research Methods: Towards a Pluralist Methodology”, Information Systems Research, 12(3), 240-259

Neuman, W.L. (2000) Social Research Methods - Qualitative and Quantitative Approaches, 4th ed. Allyn and Bacon 
Parr, A., Shanks, G. and Darke, D. (1999) "Identification of necessary factors for successful implementation of ERP systems”, in O. Ngwenyama, L.D. Introna, M.D. Myers and J.I. DeCross (eds.) New Information Technologies in Organisational Processes, Boston: Kluwer Academic Publishers, 99-119

Sarker, S. and Lee, A.S. (2000) "Using a Positivist Case Research Methodology to Test Three Competing Theories-in-Use of Business Process Redesign”, Proceedings of the International Conference on Information Systems, Brisbane, 414-425

Shanks, G., Rouse, A. and Arnott, D. (1993) A Review of Approaches to Research and Scholarship in Information Systems, Proc. $4^{\text {th }}$ Australian Conference on Information Systems, Brisbane, 29-44

Yin, R.K. (1994) Case Study Research: Design and Methods, 2nd edition, Sage Publications, Thousand Oaks 